Revue

Revue de l'histoire des religions

de Ihistoire des religions

3 | 2018

Varia

Christian JAMBET, Le gouvernement divin. Islam et conception politique du monde

Paris, CNRS Éditions, 2016

Mathieu Terrier

\title{
CpenEdition
}

Journals

Édition électronique

URL : http://journals.openedition.org/rhr/9205

DOI : 10.4000/rhr.9205

ISSN : 2105-2573

Éditeur

Armand Colin

Édition imprimée

Date de publication : 1 septembre 2018

Pagination : $575-577$

ISBN : 978-2-200-93188-9

ISSN : 0035-1423

Référence électronique

Mathieu Terrier, "Christian JAMBET, Le gouvernement divin. Islam et conception politique du monde », Revue de l'histoire des religions [En ligne], 3 | 2018, mis en ligne le 01 septembre 2018, consulté le 15 janvier 2021. URL : http://journals.openedition.org/rhr/9205; DOI : https://doi.org/10.4000/rhr.9205

Ce document a été généré automatiquement le 15 janvier 2021.

Tous droits réservés 


\section{Christian JAMBET, Le gouvernement divin. Islam et conception politique du monde}

Paris, CNRS Éditions, 2016

Mathieu Terrier

\section{RÉFÉRENCE}

Christian JAMBET, Le gouvernement divin. Islam et conception politique du monde, Paris, CNRS

Éditions, 2016, 470 p., 23 cm, $26 €$, ISBN 978-2-271-06996-2.

1 À la lecture du titre et du sous-titre, un lecteur non familier des travaux de Christian Jambet pourrait croire que l'ouvrage fait état d'une philosophie politique de l'islam. Il serait alors éclairé par le troisième titre n'apparaissant qu'à la page 5 : «Théologie de Mullā Șadrā». Car c'est bien d'une théologie qu'il s'agit et non d'une doctrine politique; de l'œuvre d'un penseur singulier et non de l'expression de l'islam en général. Regroupant des études parues indépendamment, ce livre est le cinquième que Ch. Jambet consacre à Mullā Șadrā (m. 1640), penseur iranien de langue arabe et de confession shīite duodécimaine, sans doute " l'un des plus grands penseurs de l'islam » (p. 7) comme il le démontre encore après L'Acte d'être (Paris, 2002), sur son ontologie, et Mort et résurrection en islam (Paris, 2008), sur son eschatologie.

2 La théologie de Mullā Șadrā, suivant les analyses de l'auteur, s'articule en quatre thèses : - 1/ L'essence de Dieu est toute chose (I, chap. 2). - 2/ C'est le mode d'être de toutes choses que d'être gouvernées par Dieu, selon différents modes dont le supérieur est l'émanation (fayd) au sens de Plotin et l'inférieur, le gouvernement politique du Prophète (I, chap. 1). - 3/ Le seul gouvernement, non seulement légitime, mais réel, est le gouvernement divin, exercé de manière manifeste et/ou cachée par les prophètes, les imāms et les "gnostiques » ('urafä') (III, chap. 2). - 4/ Ce gouvernement n'a pas pour finalité la vie de ce monde mais la vie dernière (III, chap. 3 et 4). La troisième thèse rend 
donc raison du titre de l'ouvrage: la "théologie de Mullā Șadrā » est bien une philosophie du "gouvernement divin ». Mais le livre montre que ce système constitue à la fois le parachèvement et la ruine de la «théologie politique » au sens de Carl Schmitt (p. 65-73), l'antagonique de la «spiritualité politique» aperçue par Michel Foucault dans la révolution islamique iranienne (p. 313), en bref, l'antidote philosophique à tout «islamisme politique». Rappelant que l'ayatollah Khomeiny était lui-même "un lecteur et un enseignant de l'œuvre de Mullā Șadrā», Ch.Jambet retourne implacablement cette œuvre contre la prétendue "souveraineté du théologien juriste " et l'hégémonie de la religion exotérique (p. 73 et 448). C'est dire si ce livre entend à la fois rendre justice au philosophe Mullā Șadrā et faire œuvre utile pour notre époque.

3 Les deux chapitres de la première partie caractérisent non pas la mais les "Théologies" de Mullā Șadrā, les "modèles de gouvernement divin» qui sont les modes d'intelligibilité de l'être. La " conception politique du monde » évoquée dans le titre de l'ouvrage conjoint le schème cosmopolitique platonicien avec la structure duelle shīite de l'ésotérique et de l'exotérique, et accorde une telle extension à la souveraineté divine que la politique humaine, fût-elle exercée par ses détenteurs légitimes prophètes ou imāms -, n'apparaît plus que comme l'ombre de la direction spirituelle en laquelle consiste l'essence de la prophétie et de l'imamat (thème développé dans la partie III, chap. 1). L'auteur révèle ainsi en Mullā Șadrā le grand penseur du drame historique de la théologie politique en islam shīite, de «la crise intérieure de cette religion, naissant de la non-réconciliation de l'exotérique et de l'ésotérique » (p. 73). En effet, les imāms shīites (VII $-\mathrm{IX}^{\mathrm{e}}$ siècles), qui revendiquaient d'abord l'autorité spirituelle et temporelle, furent violemment écartés du pouvoir et firent de leur religion un ésotérisme en définissant leur souveraineté (walāya) comme le sens caché de la prophétie. Quand le shīisme duodécimain fut proclamé religion d'État par le premier shah safavide en 1501, six siècles après l'entrée en " occultation » (ghayba) du douzième imām, les prérogatives exotériques, juridiques et religieuses de celui-ci furent accaparées par des juristes-théologiens pratiquant l'ijtihād, l'interprétation de la Loi. L'ancien maître de Mullā Șadrā, Mīr Dāmād († 1631), à qui il devait son programme théologique (p. 8-14), soutenait en théorie comme en pratique cette «représentation générale de l'imām ». Mullā Șadrā, pour sa part, condamnait ce qu'il tenait pour une dégradation de l'imamologie et visait à rendre à celle-ci, par la philosophie, sa nature spirituelle. Si sa critique est parfois voilée, relevant d'un "art d'écrire dans la persécution » selon le paradigme de Leo Strauss (p. 281), elle devient ouverte quand le philosophe expulse le juriste-théologien hors de la religion vraie, dans les « ténèbres sataniques » (p. 444 et 447).

Mais est-il si certain que la pensée de Mullā Șadrā soit d'abord une "conception politique du monde"? Parmi les cinq courants de pensée fournissant ses fils à la "tapisserie sadrienne", selon la belle image employée p. 18, ces courants que sont le néoplatonisme tardo-antique, l'imamologie shīite, la falsafa fārābienne et avicennienne, la métaphysique soufie d'Ibn al-'Arabī (m.1240) et l'œuvre syncrétique de Ḥaydar Āmulī (m. ap. 1385), le premier et les deux derniers semblent relativement étrangers au schème gouvernemental. Suivant les analyses de $\mathrm{Ch}$. Jambet, on pourrait voir le principal intérêt philosophique et théologique de cette œuvre, au-delà de sa critique de la "théologie juridique ", dans son rapport paradoxal, fait de fidélité et d'audacieuse liberté, à l'enseignement des pères de sa religion, ces imāms tenus pour infaillibles. Déjà sa thèse fondamentale, "l'essence de Dieu est toute chose ", semble 
contredire le credo du shī'isme selon lequel l'essence de Dieu est inconnaissable (p. 78), et c'est au moyen d'un modèle théophanique hérité d'Ibn al-'Arabī, un penseur non shỉite, que Mullā Șadrā harmonise les deux plans. Ce syncrétisme méthodique brille à travers l'ensemble du livre.

5 La deuxième partie, intitulée "Exégèses ", là encore au pluriel, se concentre sur les ouvrages où Mullā Șadrā commente les Écritures saintes shīites, soit le Coran et le Hadith des imāms - ce dernier étant, pour une large part, une exégèse du Coran. Selon la doctrine shīiite originelle, l'herméneutique de la Révélation était une prérogative exclusive de l'imām. Mais pour Mullā Șadrā, il incombe au véritable philosophe, en période d'occultation, de suppléer prophètes et imāms dans leur enseignement (p. 149), et de faire de la philosophie ou de la "gnose " ('irfān) «la discipline exégétique par excellence » (p.157). Si le philosophe critiquait la représentation de l'imām sur le plan juridico-religieux et politique, c'était donc pour mieux l'assumer sur le plan spirituel. Son herméneutique, à la fois rationnelle et symbolique, se démarque autant du littéralisme que de l'exégèse « excessive » rejetant le sens littéral du texte (p. 163-166). Après son «optimisme cosmologique et métaphysique », ce que l'on pourrait appeler l'optimisme herméneutique de Mullā Șadrā vient ainsi balancer son "pessimisme politique » (p.67) : du point de vue de l'histoire, il conclut à la «non-réconciliation de l'exotérique et de l'ésotérique ", mais du point de vue de l'herméneutique, c'est-à-dire de la continuité de la prophétie et donc du gouvernement divin, il fait toujours valoir une " réconciliation de la lettre et de l'esprit ». Appliquée au verset coranique 2, $255 \mathrm{dit}$ "du Trône » (chap. 2, p. 171-230), comme à un hadith imamite sur la création des Noms divins (chap. 3, p. 231-260), son exégèse a pour centre de gravité le thème de l'Homme parfait comme « image de Dieu» (p. 167), typifié sur les plans exotérique et ésotérique par le Prophète et l'Imām. Dans ce concept d'Homme parfait, Mullā Ṣadrā synthétise des traditions shî'ites, hellénistiques et soufies, où l'influence d'Ibn 'Arabī et de son passeur shỉite Ḥaydar Âmulī est encore déterminante (p. 106-107).

6 La troisième partie de l'ouvrage est consacrée à cet Homme parfait, « Le dieu humain ». Ses trois chapitres portent principalement sur les notions de prophétie et d'imamat. Dans la doctrine originelle du shí'isme imamite, qui se distingue en cela du sunnisme majoritaire, toutes deux possèdent un sens exotérique, celui de l'action historique et du pouvoir politique, et un sens ésotérique, celui de la pédagogie spirituelle et de la mission eschatologique. Mullā Șadrā y est fidèle en n'opposant pas mais en hiérarchisant les niveaux de l'autorité exotérique et de l'autorité ésotérique. Sans contester la nécessité du droit pénal, de la sharīa comme «fouet de Dieu » (p. 367), il soutient la dépendance ontologique de la législation à l'égard de la prophétie et la nature foncièrement spirituelle de celle-ci. L'auteur développe pourtant, dans le dernier chapitre, l'idée que pour Mullā Șadrā, la « religion du [véritable] savant » et la "religion des ignorants» sont au fond irréconciliables, et conclut son livre sur une dernière condamnation $\mathrm{d}^{\prime}$ " un pouvoir religieux exotérique [...] isolé de l'ésotérique " (p. 448). Le pessimisme politique l'emporte finalement sur l'optimisme herméneutique. On peut le regretter, mais c'est sans doute le signe qu'un philosophe authentique Ch. Jambet lui-même, après Mullā Ṣadrā - sait aussi être un témoin lucide de l'histoire. 


\section{AUTEURS}

\section{MATHIEU TERRIER}

Centre national de la recherche scientifique. 